\title{
Research on outdoor environment renewal for the aged in residential area_A case study of a residential area in Jinan
}

\author{
Yan Wang ${ }^{1}$, Xiao Wang ${ }^{1 *}$ \\ ${ }^{1}$ School of Civil Engineering and Architecture,University of Jinan,Jian 250022,China
}

\begin{abstract}
The model of home-based care in residential areas has gradually become an important way of providing for the aged in the age of aging in China, and more attention has been paid to the aging and renewal of existing residential areas. Taking the outdoor environment of residential areas as the research object, this paper analyses the environmental status quo of a residential area in Jinan through field investigation, and puts forward suggestions for aging renovation from the aspects of outdoor landscape system, road traffic system and supporting facilities of residential areas, so as to provide references for residential renovation.
\end{abstract}

\section{The Introduction}

According to statistics, by the end of 2017 , the number of people aged 60 or above in China had reached 240 million, accounting for $17.3 \%$ of the total population. ${ }^{[1]}$ The characteristics of "getting old before getting rich" are remarkable ${ }^{[2]}$, and the elderly tend to "acquaintance society"[3]. With the increasingly severe aging, China has put forward the "9073" pension model in combination with the actual conditions, which mentioned that $90 \%$ of the elderly are supported by social services through homebased nursing service.It can be seen that aging in place model ${ }^{[4]}$ in residential areas will become the mainstream way for urban residents to provide for the aged.However, the current situation of existing residential areas in China is worrying. Due to the lack of timely management and maintenance, serious aging of buildings, serious lack of infrastructure in residential areas, and deterioration of outdoor public environment, it is difficult to provide the conditions required for home-based care model.Based on this, this paper attempts to conduct field research on the outdoor environment of Qinglong Backstreet community, analyze and summarize its current problems, and put forward appropriate suggestions for the renewal of aging, so as to provide some references for the renewal of residential environment of China's home-based care model.

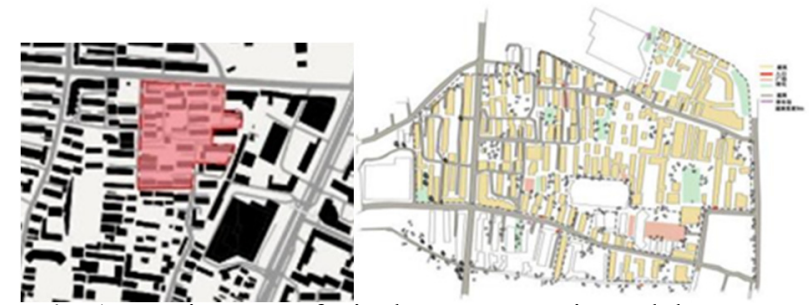

Fig. 1.Location map of Qinglong Community and the current situation of the environment outside the community. (Picture source, drawn by the author)

\section{Investigation on the current situation of outdoor environment in residential areas}

Taking Jinan city as the research scope, Qinglong Backstreet District, an existing residential area with a prominent aging problem, was selected as the research object.The research methods include field survey, questionnaire survey and online survey. The research content includes outdoor landscape system, road traffic system and supporting facilities of existing residential areas.

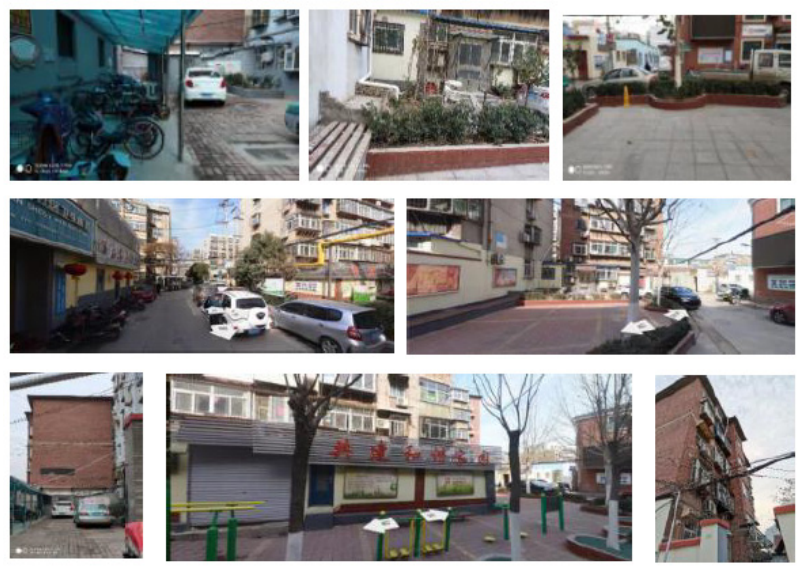

Fig. 2.The current situation of the community environment. (photo sources, taken by the author and Baidu Map) 


\subsection{Residential Situation}

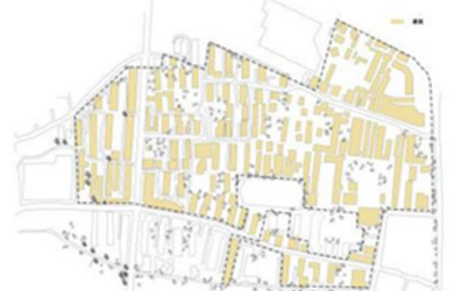

Fig. 3.House analysis diagram. (Picture source, drawn by the author)

The residential buildings in The Qinglong Back Street community of Jinan were built in batches from the 1980s to the early 21 st century, which was a relatively early residential community in Jinan. This community has a favorable geographical location. It is adjacent to the Peace Campus of Shandong Jianzhu University in the south, the central campus of Shandong University in the northeast, Daming Lake Scenic area in the west, Jinan central Hospital in the east, and several shopping centers. There are many bus stops and convenient transportation. The whole residential area is an open determinant layout, with traffic for people and cars.There are many original residents in the residential area, and the proportion of middle-aged and elderly residents is large.

\subsection{Tight road and parking area}

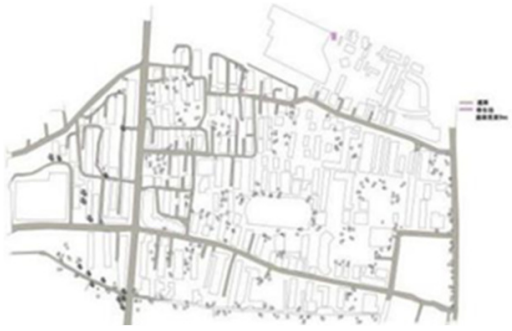

Fig. 4.Road analysis diagram. (Picture source, drawn by the author)

Due to the increase in the number of vehicles and the number of shopping malls nearby, especially the rush hour, the ground parking in the community is relatively tight, and the regional traffic pressure is great.The community is close to the Daming Lake scenic area. On weekends and holidays, there are a lot of external vehicles to visit the scenic area. The traffic pressure around the community is heavy, causing congestion and making it difficult for residents to travel.

The roads inside the community are circular, with many end-end roads and low land utilization, which affects the traffic convenience. The lack of activity space in the open community and the random parking of vehicles from the front to the back of the building to the road have a great impact on residents' travel, and the elderly are not safe to travel.People and cars are mixed on the road, and barrier-free road debris is piled everywhere, which is difficult to meet the travel needs of the elderly.It is easy to cause congestion because of the non-motor vehicle sheds built in disorder.Poor lighting of street lamps, serious damage to the road surface at the well cover of engineering pipelines, uneven road surface, not only affect the appearance of the community, but also difficult to ensure the safety of the elderly travel.

\subsection{Lack of landscape and activity space}

The squares are mainly scattered in the open space between residential buildings, with low and uneven coverage, low service level and simplistic functions.Greening is arranged at the edge of the square to define the boundary of the square. Due to the lack of regular management, the green land is piled up by residents with garbage and sundry things, and the residential area presents an aging and disordered state.

There is no clear landscape center, and the residential identification is not strong, which affects the elderly's environmental quality of natural life, psychological security, happiness, and serious shortage of public green space and activity space. The residential environment is short of pavilions, seats and other facilities for residents to gather and rest. The pipeline laying conflicts with the greening land, which affects the viewing degree of the greening and has potential safety hazards.

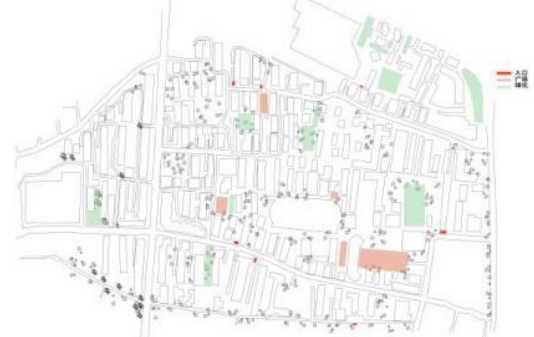

Fig. 5.Landscape analysis diagram. (Picture source, drawn by the author)

\subsection{Aging of buildings and supporting facilities}

The residential area is mainly composed of 6 floors, brick and concrete structure, red brick exterior wall, and most residential buildings are externally laid with insulation layer.The space between buildings is 10 meters, the walls are dirty, the pipeline facilities are exposed, and the local wall tiles are missing.

There is a lack of barrier-free facilities in the residential area, lack of management of entrances and exits, serious sanitation problems, garbage cans are left in disorder, unclear door signs and lack of identification. The public service facilities are mainly commercial and social service facilities, while the elderly service facilities and social welfare facilities are insufficient, which need to be solved and optimized urgently.

\section{Outdoor environment suitable for aging and renewal strategy}

Based on the three needs of the elderly: psychological needs, physiological needs, and behavioral activity needs, the existing strategies of community age-appropriate external environment were put forward -- material ageappropriate construction, spiritual age-appropriate construction.The Five principles of old-age care developed in Sweden - generalization, day-by-day, treating people as a whole, self-determination, influence 
and participation, and appropriately managed actions.From the three aspects of physical weakness, should increase the rest facilities, reduce the vertical traffic frequency, from the hardware facilities and software supporting comprehensive consideration, easy to identify, easy to reach, easy to communicate, barrier-free, safety and meet the physiological and psychological needs of the elderly.

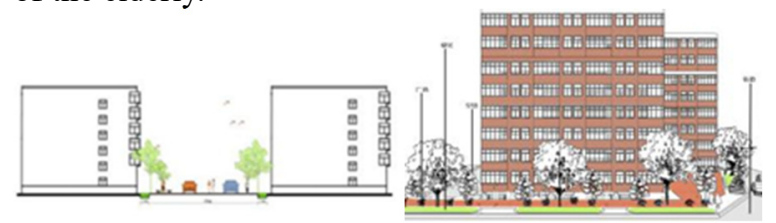

Fig. 6. Schematic diagram of human and vehicle separation. Fig. 7..Schematic diagram of human and vehicle separation. (Picture source, drawn by the author)

\subsection{Updating roads and parking Spaces}

To strengthen the existing phenomenon of disorderly parking treatment, the demolition of the indiscriminate construction of car sheds, residential groups centralized layout of non-motor vehicle parking Spaces.The separation of people and vehicles is adopted to reduce endend roads, improve land utilization and travel convenience, and meet the emergency response of ambulances and fire trucks.Clear parking space to make the road as smooth and straight as possible.Adding vertical parking spaces to solve the problem of "less land and more cars" and control the inflow of external vehicles, and relieve the traffic pressure inside and outside the community. The road is repaired to make it smooth, and the ground is paved with non-slip materials to meet the behavioral needs of the elderly.

\subsection{Enrich the greening and outdoor activity space}

Outdoor activities of the elderly can be divided into three aspects: exercise, rest and special activities. The required functional space can be added around the original square or the reused abandoned building (boiler, workshop).

For the reuse of open Spaces of different areas and terrains, different levels of "pocket parks" are arranged accordingly to improve the coverage rate of greening and square and expand the service scope."Pocket Park" sets up activity venues with different private densities: semiprivate, semi-public and public places. The environmental design experiences the regional cultural characteristics, retains the original elements that reflect the regional characteristics, keeps the familiarity of the living community, gives the elderly a sense of belonging, and creates a "natural retirement community" [5] to increase the variety of green plants satisfying the northern climate, improve the sense of landscape design, and enrich the paving way.Adopt bright and concise patterns, colors and sounds, lighting to shape landscape nodes, entrances and exits, etc. for easy identification design.Lack of pavilions, seats and other facilities, piping and greening land conflict.Expand the general scale of the site, take into account the use of other groups, improve the utilization of
land.Barrier-free treatment should be carried out in the main areas of elderly activities. The steps are equipped with a single handrail, which focuses on the junction between the platform and the ramp to meet the turning radius of the wheelchair.

\subsection{Upgrade supporting facilities for aging}

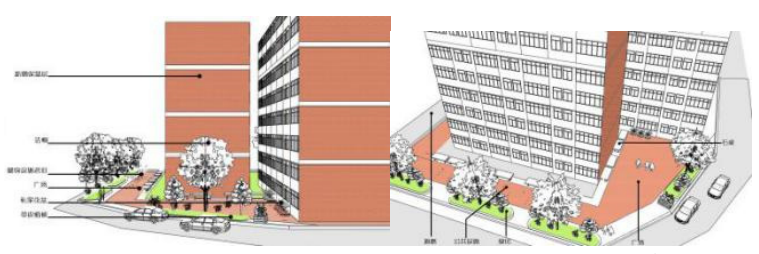

Fig.8.Schematic diagram of landscape renovation (Picture source, drawn by the author)

Improve the property management service system, focusing on three aspects: garbage collection, aging of water and electricity pipelines, and access control for internal and external personnel.In order to facilitate the elderly upstairs and downstairs, according to its existing structure, can consider the external elevator frame installation.Replace the door and window components, reduce the heat conduction speed in winter, improve the capacity of heat preservation, heat insulation and sound insulation. The supporting endowment system provides exchange activities such as shared garden and kitchen according to the level configuration of residential area, residential area and residential group.Housing for elderly care, living services, health care and rehabilitation, and recreational facilities should be added to promote the participation of the elderly, so as to achieve the existing community state of sharing, co-construction and symbiosis.

\section{Conclusion}

This paper takes the present situation of existing communities in Jinan city as the object of study and focuses on the design of age-appropriate transformation of the external environment of public space. This paper deals with the lack of senility in square, road and afforestation, and puts forward the strategy of senility improvement in outer space environment from the aspects of psychology, physiology and behavior of the elderly. The content of the age-appropriate transformation of the outer space environment of the regional difference and the urban-rural difference between the old and the new needs further study.Making use of the original community to reform for the aged is not only beneficial to the vulnerable groups, improving the living environment, but also can relieve the pressure of China's old-age care problems.

\section{Acknowledgement}

This research was financially supported by Shandong University Students Innovation and Entrepreneurship training platform(S201910427013X). 


\section{References}

1. Source: National Bureau of Statistics, PRC.

2. Lu Fei, Luo Jingjing, Kang Wen.Research on the Strategy of Aging Improvement based on universal Design of Cold Region Housing Environment -- A case study of Lilac Home in Harbin.

3. Jingjing.Children's Wonderlan--Stockholm Experience [M] Shanghai: Shanghai Far East Publishing House, 2016.

4. BEDNEY B J,GOLDBERG R B,JOSEPHSON K.Aging in place in naturally occurring retirement communities:transforming aging through supportive service programs[J].Journal of Hosing for the Elderly,2010,24(3-4):304-321.

5. HUNT M E,GUNTER-HUNT G.Naturally occurring retirement communities[J].Journal of Housing for the Elderly, 1986,3(3-4):3-2. 